\title{
USE OF SUPERPLASTIC DEFORMATION AND DIFFUSION WELDING TO FORM A TEE DESIGNED WITH A COMPLEX SET OF INTERNAL STIFFENING ELEMENTS
}

\author{
A. K. Shmakov, ${ }^{1}$ V. V. Mironenko, ${ }^{1}$ \\ K. K. Kirishina, ${ }^{1}$ and V. V. Kotov ${ }^{2}$
}

UDC 621.7 .04

\begin{abstract}
A method is described for making a tee designed with a complex set of internal stiffening elements. The article describes the main stages of the modern process of pneumothermal forming in the superplastic regime with the use of diffusion welding. The production of a tee by superplastic pneumothermal forming after diffusion welding is modeled and the calculated results are presented.

Keywords: pneumothermal forming of sheet parts, superplastic effect, tube parts made from sheets.
\end{abstract}

The complexity of gas-distribution systems and oil-conditioning systems that separate out liquids requires the use of complicated tubular parts which separate different flows with the use of internal design elements. Parts of this type can take the place of a collection of tubular parts which do not have flow-separation elements. In this investigation, we examine one method of making tubular parts designed with a complex set of internal stiffening elements. As an example, we will examine a tee in which the large tube has a diameter of $30 \mathrm{~mm}$ and the branch has a diameter of $25 \mathrm{~mm}$ (Fig. 1).

Such a part is distinguished by the complexity and uniqueness of its design and cannot be made by the usual method. We will examine a variant for making the part which uses both pneumothermal forming in the superplastic regime and diffusion welding.

The first step is the zonal application of an anti-welding coating to the location where diffusion welding will take place.

In the next step, the sheets that make up the part are arranged from top to bottom in the order shown in Fig. 2 and are welded together at their ends. The resulting semifinished product is placed in the fixture of a hydraulic press to perform the operation of pneumothermal forming in the superplastic regime. The operation is carried out at a temperature of $910^{\circ} \mathrm{C}$ and a pressure on the order of $1 \mathrm{MPa}$. It results in diffusion welding of the sheets.

We modeled superplastic pneumothermal forming in the software package PAM-STAMP 2G, which was developed by the French company the ESI Group. The calculations were performed using a material model in which the stresses depend directly on the strain rate [1]:

$$
\sigma=K \dot{\varepsilon}^{m}
$$

where $K$ is a proportionality factor; $\dot{\varepsilon}$ is the strain rate; $m$ is the strain-hardening modulus; and $\sigma$ is the stress.

\footnotetext{
${ }^{1}$ Irkutsk State Technical University, Irkutsk, Russia.

${ }^{2}$ Russian Affiliate of the ESI Group; Yeltsin Ural Federal University (UrFU), Ekaterinburg, Russia; e-mail: viacheslav.kotov@ esi-group.com.
}

Translated from Metallurg, No. 3, pp. 24-27, March, 2013. Original article submitted March 11, 2013. 


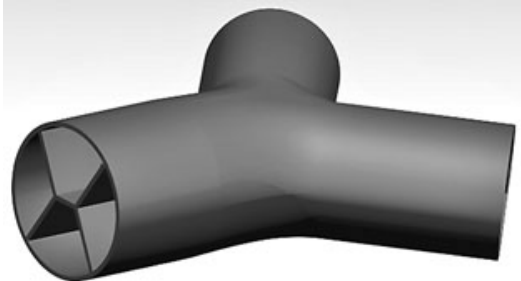

View 1

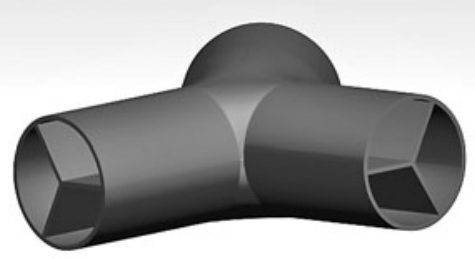

View 2

Fig. 1. Tee designed with a complex set of internal stiffening elements.

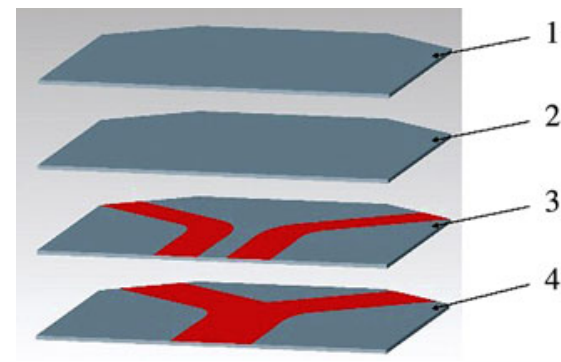

Fig. 2. Enumeration of the semifinished products.

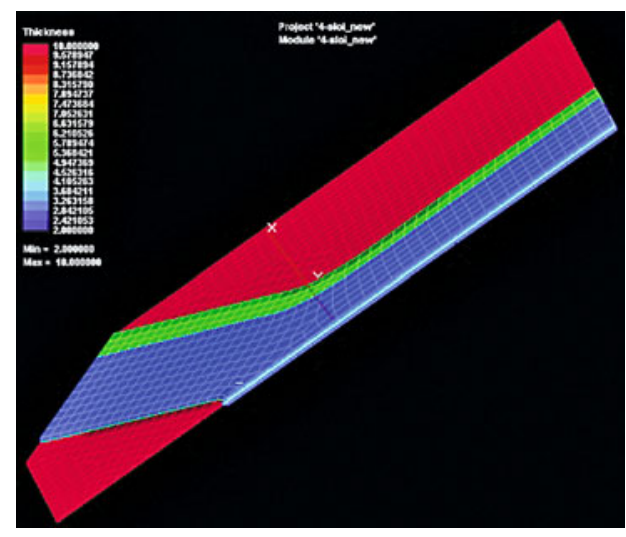

Fig. 3. Cross-sectional distribution of the thickness of the packet of semifinished products after diffusion welding.

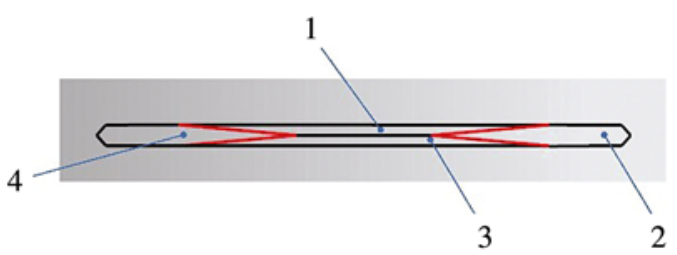

Fig. 4. Schematic designation of the cavities.
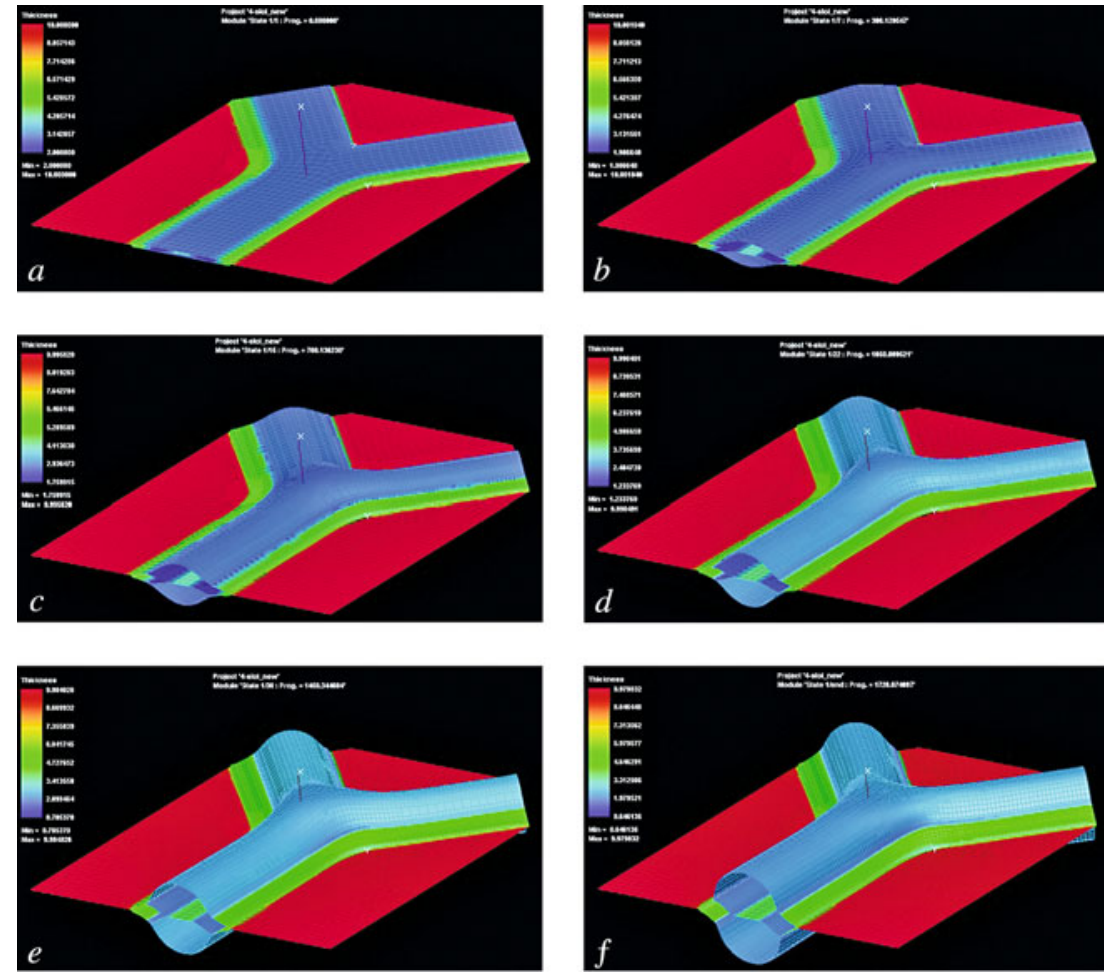

\begin{tabular}{|c|c|c|c|}
\hline \multirow{2}{*}{ View } & \multirow{2}{*}{ Time, sec } & \multicolumn{2}{|c|}{ Thickness, mm } \\
\cline { 3 - 4 } & & Maximum & Minimum \\
\hline$a$ & 0 & 10 & 2 \\
\hline$b$ & 300 & 10 & 1.98 \\
\hline$c$ & 705 & 10 & 1.75 \\
\hline$d$ & 1050 & 10 & 1.23 \\
\hline$e$ & 1450 & 10 & 0.78 \\
\hline$f$ & 1720 & 10 & 0.64 \\
\hline
\end{tabular}

Fig. 5. Forming sequence in the first stage. 

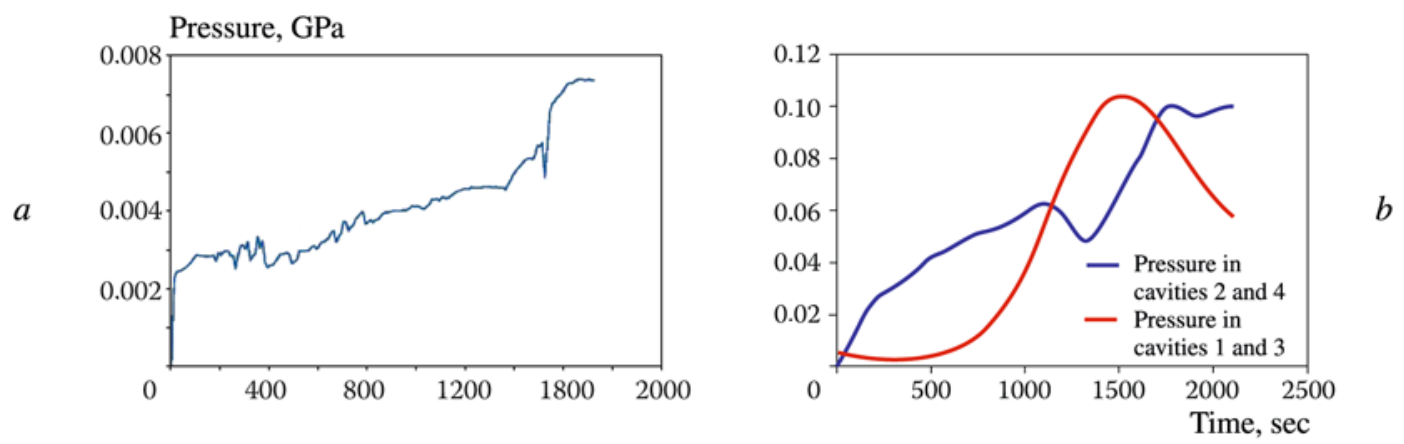

Fig. 6. Graph of the pressure change in the first $(a)$ and second $(b)$ forming stages.
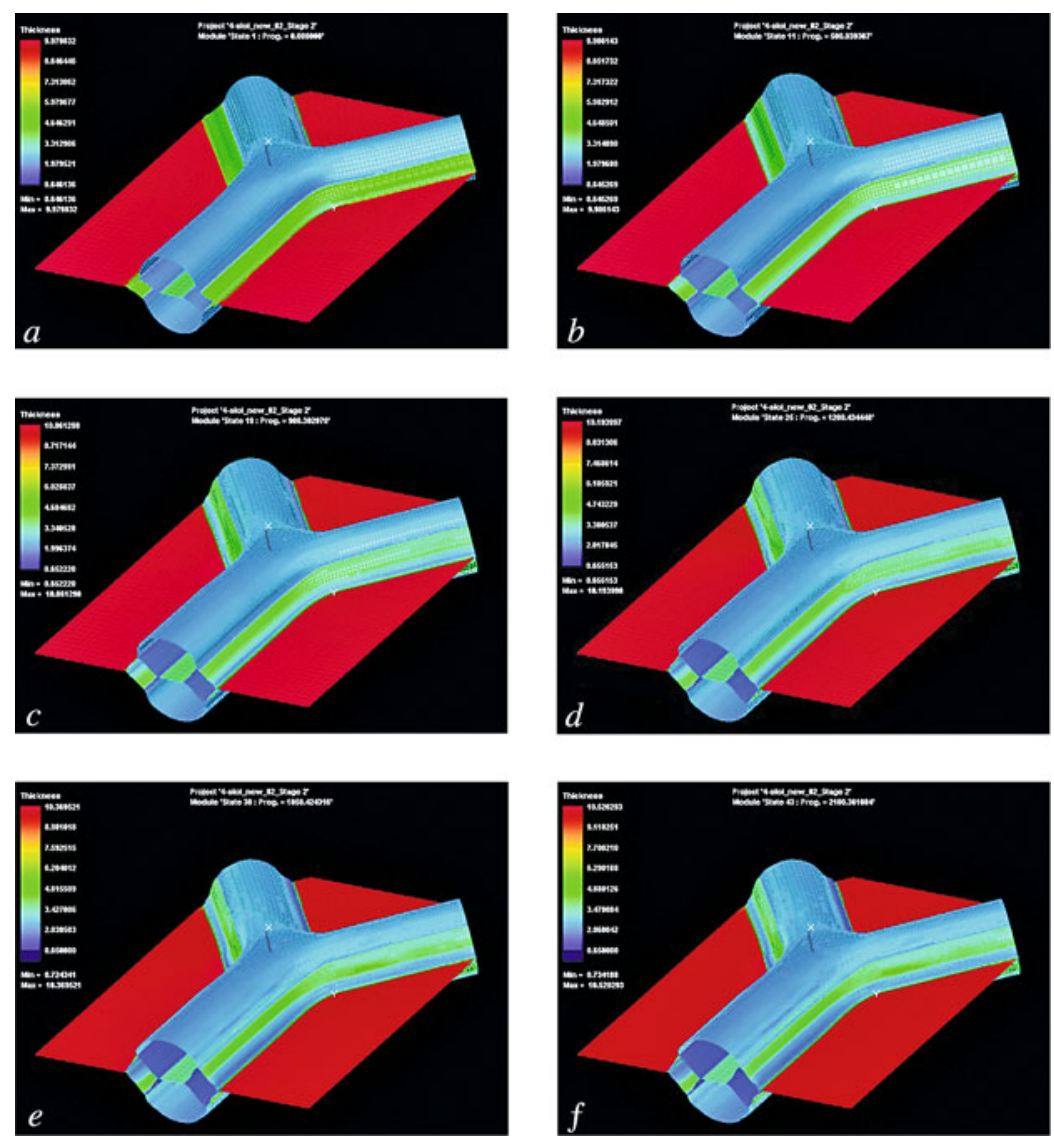

\begin{tabular}{|c|c|c|c|}
\hline \multirow{2}{*}{ View } & \multirow{2}{*}{ Time, sec } & \multicolumn{2}{|c|}{ Thickness, mm } \\
\cline { 3 - 4 } & & Maximum & Minimum \\
\hline$a$ & 0 & 10 & 0.64 \\
\hline$b$ & 500 & 10 & 0.64 \\
\hline$c$ & 900 & 10 & 0.65 \\
\hline$d$ & 1200 & 10.2 & 0.65 \\
\hline$e$ & 1850 & 10.3 & 0.65 \\
\hline$f$ & 2100 & 10.5 & 0.64 \\
\hline
\end{tabular}

Fig. 7. Forming sequence in the second stage.
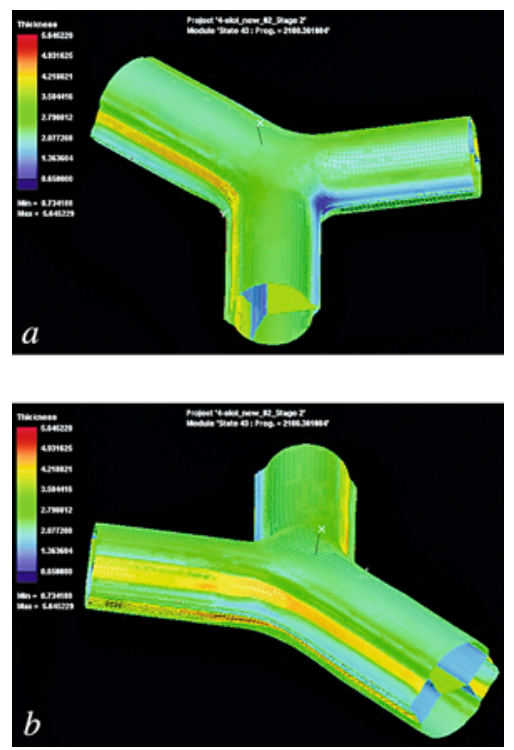

Fig. 8. Thickness distribution on the part: a) view $1 ; b$ ) view 2 . 
The following parameters were used to create a model made of alloy VT20:

- elastic modulus - $112 \mathrm{GPa}$;

- Poisson's ratio - 0.333;

- density $-4.5 \cdot 10^{-6} \mathrm{~kg} / \mathrm{mm}^{3}$;

- proportionality factor $-0.597488 \mathrm{GPa}$;

- strain rate $-0.0016[2]$;

- strain-hardening modulus -0.42 [2].

The thicknesses of the sheets that were used, mm: 1st sheet $-3 ; 2$ nd sheet $-2 ; 3$ rd sheet $-2 ; 4$ th sheet -3 .

Figure 3 shows the model of the packet comprising the semifinished product. The packet is shown in cross section at the moment it is opened. The figure also shows the distribution of thickness after the sheets have been diffusion-welded.

The forming operation is performed by creating pressure in all of the cavities in the packet with the use of a constant strain rate conforming to the schedule for the first stage. The operation is performed in such a way that the part of the packet colored red (Fig. 4) is deformed only as a result of displacement of the outer sheets. This is accomplished by applying pressure to both sides of these sheets simultaneously.

Figure 5 shows the sequence followed in forming the part during the first stage, while the graph in Fig. $6 a$ shows the change in pressure at this stage.

In the second stage, pressure is fed into cavities 1 and 3 in accordance with the red curve and into cavities 2 and 4 in accordance with the blue curve (Fig. 6b).

Figure 7 shows the forming sequence in the second stage with the given loading curves (Fig. 6b).

Modeling of the forming operation by the above-described method yields a part with values of $0.65 \mathrm{~mm}$ and $0.64 \mathrm{~mm}$ for minimum wall thickness (Fig. 8).

Conclusion. The modeling results obtained here can be used to make parts of the given type. The practical introduction of parts designed with a complex set of internal stiffening elements will make it possible to design aircraft systems employed in the distribution of gases and liquids, since the elements allow the parts to separate different flows. The presence of the stiffening elements also gives the parts better strength characteristics, which enhances the reliability of aircraft systems in general.

\section{REFERENCES}

1. E. N. Chumachenko, O. M. Smirnov, and M. A. Tsepin, Superplasticity: Materials, Theory, Technology [in Russian], KomKniga, Moscow (2005).

2. O. M. Smirnov, Metal-Shaping in the State of Superplasticity [in Russian], Mashinostroenie, Moscow (1979). 